prevent permanent joint damage (1). However, it has been shown that only $20 \%$ of the patients are seen within the first three months, and the median delay in general practice has been estimated to 4 months (range 2-9) (2).

Objectives: To explore the barriers in diagnosing RA from the general practitioners' (GPs) perspective.

Methods: We conducted a qualitative study based on focus group interviews. We recorded the interviews digitally and transcribed verbatim. The transcribed interviews were analyzed based on content analysis (3), by using Nivo 12. Sample size was determined by thematic saturation.

Results: In total ten GPs participated in three different focus groups. $40 \%$ were female, mean age was 53 years (range 37-64), and mean year since specialist authorization as GP was 16 years (range 5-23). $60 \%$ of the GPs worked in a practice located within the referral area of a university hospital; the remaining within the referral area of a regional hospital.

Four themes emerged in the analysis: 1) When the patient is not a text book example, referring to the difficulty of identifying relevant symptoms among all clinical manifestations from the joints as described by the patients, 2) The importance of maintaining the gatekeeper function, referring to the societal perspective, and the GPs responsibility to refer the right patients to secondary care, 3) Difficulties in referral of patients to the rheumatologist, referring to perceived differences in the collaboration with rheumatologists. The GPS experienced that it was sometimes difficult to be assisted by rheumatologists, especially when the clinical picture was not 'clear cut'. Finally, (4) Para-clinical testing, can it be trusted? referring to challenges on the evaluation of especially biomarkers.

The overarching theme was: Like finding a needle in a haystack, covering the GPs difficulties in detecting RA among the many patients in general practice who appear to be well and at the same time have symptoms very similar to RA. Conclusion: The GPs experienced that RA was a difficult diagnosis to make. The immediate challenge was that RA patient's initial symptoms often resembled those of more common and less serious conditions, and that investigative findings such as biomarkers can be negative at the early state of the disease. At the same time, the collaboration with rheumatologists was sometimes seen as a hurdle, when the clinical picture was not 'clear cut'.

In order to facilitate earlier diagnosis of RA in general practice, the GPs and rheumatologists need to focus on these barriers by strengthening mutual information and collaboration.

Physicians should remain vigilant to patients who have conditions that do not resolve as expected with treatment, who have symptoms that persist, or who do not look well despite negative investigative findings.

References:

[1] Aletaha D, et al. JAMA, Oct 2018.

[2] Kiely P, et al. Rheumatology, Jan 2009.

[3] Braun V. Qualitative research in psychology. 2006, 3(2), 77-101

Disclosure of Interests: Anne Sofie Lundberg: None declared, Bente Appel Esbensen: None declared, Ellen-Margrethe Hauge Speakers bureau: Fees for speaking/consulting: MSD, AbbVie, UCB and Sobi; research funding to Aarhus University Hospital: Roche and Novartis (not related to the submitted work)., Annette de Thurah Grant/research support from: Novartis (not relevant for the present study)., Speakers bureau: Lily (not relevant for the present study). DOI: 10.1136/annrheumdis-2020-eular.4387

\section{SAT0652-HPR CHRONIC DISEASE MANAGEMENT AND HEALTH TECHNOLOGY READINESS OF PATIENTS WITH SYSTEMIC SCLEROSIS IN SWITZERLAND - A CROSS- SECTIONAL STUDY}

A. Kocher ${ }^{1,2}$, M. Simon ${ }^{1,2}$, C. Chizzolini ${ }^{3}$, O. Distler ${ }^{4}$, A. A. Dwyer ${ }^{5}$, P. Villiger ${ }^{2}$, U. Walker ${ }^{6}$, D. Nicca ${ }^{1,6}$. ${ }^{1}$ University of Basel, Institute of Nursing Science, Basel, Switzerland; ${ }^{2}$ Inselspital Bern University Hospital, Bern, Switzerland; ${ }^{3}$ Immunology \& Allergy, University Hospitals and School of Medicine, Geneva, Switzerland; ${ }^{4}$ University Hospital of Zurich, Zurich, Switzerland; ${ }^{5}$ Boston College, Connell School of Nursing, Massachusetts, United States of America; ${ }^{6}$ University Hospital of Basel, Basel, Switzerland

Background: People living with systemic sclerosis (SSc) often lack access to coordinated, specialized care and self-management support from qualified healthcare professionals. Such gaps lead to significant unmet health needs and inability to get preventive services. The Chronic Care Model (CCM) has been used to guide disease management across a wide range of chronic conditions. The CCM often uses e-health technologies to address self-management problems, connect patients with clinicians and reduce patient travel requirements.

Objectives: To evaluate current SSc care practice patterns and elicit patient health technology readiness to define relevant aspects and resources needed to improve SSc chronic disease management.

Methods: We employed a cross-sectional survey using the 20-item Patient Assessment of Chronic IIIness Care (PACIC) instrument to assess how aspects of SSc care align with key components of the CCM. ${ }^{1}$ Six items drawn from the ' $5 A$ ' (ask, advise, agree, assist, and arrange) model of behavioural counselling were included (all 26 items scored on 5-point scale, $1=$ never to 5=always). Acceptance of health technology was evaluated by adapting and combining questionnaires from Vanhoof ${ }^{2}$ and Halwas ${ }^{3}$. German and French speaking SSc patients $(>18$ years) were recruited from university/cantonal hospitals and the Swiss scleroderma patients' association. Participants completed anonymous paper/online questionnaires. Data were analysed descriptively.

Results: Of 101 SSc patients, most were female (76\%), spoke German (78\%) and had a median age of 60 years (IQR: 50-68). Median disease duration was 8 years (IQR: $5-15)$, spanning a range of severity (31\% limited SSc, $36 \%$ diffuse SSc, $3 \%$ overlap syndrome). One-quarter (25\%) did not know their disease subset.

The mean overall PACIC score was relatively low $(2.91 \pm 0.95)$ indicating that care was 'never' to 'generally not' aligned with the CCM. Lowest mean subscale scores related to Follow-up/ Coordination (2.64 \pm 1.02$)$, Goal setting $(2.68 \pm 1.07)$ and Problem-solving/Contextual Counselling (2.94 \pm 1.22$)$. The single items 'Given a copy of my treatment plan' $(1.99 \pm 1.38)$ and 'Encouraged to attend programs in the community' $(1.89 \pm 1.16)$ were given the lowest ratings. The ' $5 A$ ' summary score was $2.84 \pm 0.97$

In terms of technology readiness, $43 \%$ completed the survey online. Most participants owned a smartphone ( $81 \%)$, laptop (63\%) and/or desktop computer (46\%). The overwhelming majority of patients $(91 \%)$ reported using the Internet in the last year - primarily for communication (e.g. emails, text messages). Participants indicated relatively little experience with e-health applications and participating in SSc online forums or self-help groups.

Conclusion: To improve chronic disease management of SSc patients in Switzerland, current care practices warrant reengineering taking CCM components into account. Specific unmet needs relate to self-management support, help patients set individualized goals, and coordinate continuous care. Web-based technologies incorporating user-centred design principles may be a reasonable option for improving care.

References:

[1] Glasgow, RE, et al. Development and validation of the Patient Assessment of Chronic IIIness Care (PACIC). Med Care 2005; 43(5): 436-44

[2] Vanhoof, JM, et al. Technology Experience of Solid Organ Transplant Patients and Their Overall Willingness to Use Interactive Health Technology. J Nurs Scholarsh 2018; 50(2): 151-62

[3] Halwas, N, et al. eHealth literacy, Internet and eHealth service usage: a survey among cancer patients and their relatives. J Cancer Res Clin Oncol 2017; 143(11): 2291-99

Disclosure of Interests: Agnes Kocher Grant/research support from: Sandoz to support the development of an eLearning module for patients with rheu matic diseases., Michael Simon: None declared, Carlo Chizzolini Consultan of: Boehringer Ingelheim, Roche, Oliver Distler Grant/research support from: Grants/Research support from Actelion, Bayer, Boehringer Ingelheim, Com petitive Drug Development International Ltd. and Mitsubishi Tanabe; he also holds the issued Patent on mir-29 for the treatment of systemic sclerosis (US8247389, EP2331143)., Consultant of: Consultancy fees from Actelion, Acceleron Pharma, AnaMar, Bayer, Baecon Discovery, Blade Therapeutics Boehringer, CSL Behring, Catenion, ChemomAb, Curzion Pharmaceuticals, Ergonex, Galapagos NV, GSK, Glenmark Pharmaceuticals, Inventiva, Italfarmaco, iQvia, medac, Medscape, Mitsubishi Tanabe Pharma, MSD, Roche, Sanofi and UCB, Speakers bureau: Speaker fees from Actelion, Bayer Boehringer Ingelheim, Medscape, Pfizer and Roche, Andrew A. Dwyer: None declared, Peter Villiger Consultant of: MSD, Abbvie, Roche, Pfizer, Sanofi, Speakers bureau: Roche, MSD, Pfizer, Ulrich Walker Grant/research support from: Ulrich Walker has received an unrestricted research grant from Abbvie, Consultant of: Ulrich Walker has act as a consultant for Abbvie, Actelion, Boehringer Ingelheim, Bristol-Myers Squibb, Celgene, MSD, Novartis, Pfizer, Phadia, Roche, Sandoz, Sanofi, and ThermoFisher, Paid instructor for: Abbvie Novartis, and Roche, Speakers bureau: Abbvie, Actelion, Bristol-Myers Squibb, Celgene, MSD, Novartis, Pfizer, Phadia, Roche, Sandoz, and ThermoFisher Dunja Nicca: None declared

DOI: 10.1136/annrheumdis-2020-eular.3232

\section{SAT0653-HPR COMMUNITY RHEUMATOLOGY SERVICE IN THE UK - WHO BENEFITS THE MOST?}

K. Szabo-Kocsis ${ }^{1}$, M. Dare ${ }^{2} .{ }^{1}$ Connect Health Ltd., Rheumatology, Newcastle upon Tyne, United Kingdom; ${ }^{2}$ Connect Health Ltd., Newcastle upon Tyne, United Kingdom

Background: Community rheumatology $(\mathrm{CR})$ in the UK is a new form of rheumatologic service provision established in the last few years and run by few organisations such as Connect Health Ltd.

$\mathrm{CR}$ is based on the principle of sharing the management of rheumatologic patients between community service and secondary care aiming to reduce the 